\title{
FORAGING BEHAVIOR OF NATIVE HONEYBEE (APIS CERANA F.) AND EUROPEAN HONEYBEE (APIS MELLIFERA L.) ON FLOWERS OF COMMON BUCKWHEAT (FAGOPYRUM ESCULENTUM M.) IN CHITWAN, NEPAL
}

\author{
L.N. Aryal ${ }^{1}$, R.B. Thapa ${ }^{1}$, S. Tiwari ${ }^{2}$ and N.K. Chaudhary \\ ${ }^{1}$ Department of Entomology, Institute of Agriculture and Animal Science, Tribhuvan University, Kirtipur, Nepal \\ ${ }^{2}$ Department of Entomology, Agriculture and Forestry University, Chitwan, Nepal \\ Corresponding author's email: loknatharyal44@gmail.com
}

\begin{abstract}
This paper is the findings of the research conducted on foraging behavior of Native honeybee (Apis cerana F.) and European honeybee (Apis mellifera L.) on flowering buckwheat (Fagopyrum esculentum Moench) inside the cage during November 2012 to 2013 at Meghauli, Chitwan, Nepal. Apis cerana F. started their foraging activities early in the morning $(8.24 \pm 0.50 \mathrm{AM})$ and ceased late in the evening $(5.18 \pm 0.20 \mathrm{PM})$ in comparison to Apis mellifera $\mathrm{L}$., which started foraging at $8.29 \pm 0.50 \mathrm{AM}$ and ceased at $4.56 \pm 0.50 \mathrm{PM}$. The total duration of foraging per day was more in Apis cerana F. than Apis mellifera L., i.e. $8.34 \pm 0.90$ hours per day in Apis cerana $\mathrm{F}$. and $8.25 \pm 0.90$ hours per day in Apis mellifera $\mathrm{L}$. That means A. cerana $\mathrm{F}$. was $1.8 \%$ more efficient on foraging duration than A. mellifera $\mathrm{L}$. Similarly, the number of Apis cerana F. and Apis mellifera L. entering into the hive in five minutes was the highest (51.69 \pm 0.45 in Apis cerana F., and $62.81 \pm 0.45$ in Apis mellifera L.) at 12 Noon while lowest (11.24 \pm 0.11 in Apis cerana F., and 5.89 \pm 0.11 in Apis mellifera L.) at 5 PM and no activity was started at 8 AM. Likewise, the number of Apis cerana $\mathrm{F}$. and Apis mellifera $\mathrm{L}$. bees outgoing from the hive in five minutes was the highest $(42.67 \pm 0.98$ in Apis cerana F. and $48.71 \pm 0.98$ in Apis mellifera L.) at 12 Noon and the lowest ( $4.31 \pm 0.07$ in Apis cerana F. and $2.39 \pm 0.07$ in Apis mellifera L.) at 5 PM. The number of buckwheat flower visited by Apis cerana F. was highest at 10 AM while by Apis mellifera L. it was highest at 12 Noon. But, for both species of honeybees it was lowest at 4 PM. There was more time spent by Apis mellifera L. (2.37 seconds) per flower than Apis cerana F. (1.95 seconds) during floral visit. So, Apis cerana $\mathrm{F}$ is efficient in foraging and hence in pollination on buckwheat than Apis mellifera $\mathrm{L}$ suggesting buckwheat cultivation along with bee farming especially Apis cerana $\mathrm{F}$.
\end{abstract}

Key words: Apis cerana F.; A. mellifera L.; foraging; buckwheat

\section{Introduction}

Common buckwheat (Fagopyrum esculentum Moench) is one of the earliest crops domesticated in Asia. It is called a pseudo cereal because of its similar nature in uses but it is dicot plant and does not belong to true cereals, it belongs to the family Polygonaceae (Bjorkman, 1995). In Nepal, this crop occupies 10,339 ha of land area with productivity of $0.97 \mathrm{t} / \mathrm{ha}(\mathrm{MoAD}, 2012)$. It attains a height of 60 to $150 \mathrm{~cm}$ or more. It has one main stem with several branches. Flowers are red, pink or white. The leaf color ranges from pale green to dark green (Marshall and Pomeranz, 1982). The flowering in buckwheat is from bottom to top and from inside to outside of the branches.

Buckwheat, a cross pollinated, entomophilic and an indeterminate plant, seeds are brown in color and irregularshaped with four triangular surfaces. Joshi and Rana (1999) reported that flowering begins 5-6 weeks after sowing. After a flower is pollinated, a full-sized seed forms within 10 days, although that seeds need another one or two weeks to reach maturity. Seeds appear and mature earlier on the lower stem continuing up the stem as the plant matures (Rajbhandari and Bhatta, 2008).

There are two types of flowers in common buckwheat, viz. pin type with longer pistil and shorter stamens; and thrum type with shorter pistil and longer stamens. The thrum and pin type flowers produce different sized pollen grains. Honeybees can collect both types of pollen on a single foraging trip (Davydova, 1954; Bjorkman, 1995); indicating that they are effective and major pollinators of buckwheat. Buckwheat pollen is not windblown; therefore insects are necessary for the transfer of pollen. The cultivation of buckwheat along with beekeeping may produce 50 to $100 \mathrm{~kg}$ of honey per hectare (Rajbhandari, 2010). Buckwheat flowers in the first sunshine and during which time it is highly attractive to bees (Phillips and Demuth, 1922) and most of the pollination activities occur. Many factors such as the floral physiology and morphology, pollinator characteristics, as well as effects of weather 
influence the foraging behavior of honeybees. Foraging rate is one of the important factors to compare pollination efficiency of different bee species. Foraging behavior of honeybees (Apis mellifera L. and Apis cerana F.) are of great economic importance as they comprise about $80 \%$ of total insect pollination (Robinson et al., 1989).

\section{Materials and Methods}

The research was conducted during November 2012 to February 2013 in farmers' field at Meghauli-9, Dharampur, western part of Chitwan, Nepal. Field was dry at that time but lowland and near to forest areas. The experiment was laid out in plot size of $5 \times 3 \mathrm{~m}^{2}$ and caging was done with two frame bee hive of two species of honeybees (Apis cerana $\mathrm{F}$. and Apis mellifera L.). Caging was done at 5-10\% flowering up to $90 \%$ flowering. Bee colonies were fed with 1:1 sugar syrup once in a week throughout the entire pollination period. The observations were made for the different foraging parameters of honeybees continuously for flowering periods of buckwheat. The climate of the area was sub-tropical type. The average maximum and minimum temperatures were $30.20^{\circ} \mathrm{C}$ and $5.90^{\circ} \mathrm{C}$ in March 2013 and December 2012- January 2013, respectively. Relative humidity was the lowest in February $(91.10 \%)$ and the highest $(95.70 \%)$ in January 2013. There was no rainfall during November, December and February.

The design of the field experiment was Completely Randomized Design (CRD) inside the cage. The observation data were recorded, processed (by square root transformation) and analyzed by MS-Excel as well as by ANOVA procedure described by Gomez and Gomez (1984). When the F-test indicated statistical significance at the $\mathrm{P}=0.01$ and $\mathrm{P}=0.05$ level, the Duncan's Multiple Range Test was used to compare the difference of the means.

\section{Results and Discussion}

\section{Initiation and cessation of foraging by Apis cerana F. and Apis mellifera $\mathbf{L}$.}

Apis cerana $\mathrm{F}$. started their foraging activities early in the morning $(8.24 \pm 0.5 \mathrm{AM})$ and ceased late in the evening
$(5.18 \pm 0.2 \mathrm{PM})$ compared to Apis mellifera $\mathrm{L}$. which started foraging at $8.29 \pm 0.5 \mathrm{AM}$ and ceased at $4.56 \pm 0.5 \mathrm{PM}$. This is in line with Dhakal (2003) who found that A. cerana F. started foraging on buckwheat at $7.03 \pm 0.22 \mathrm{AM}$ and ceased their foraging at $4.51 \pm 0.15 \mathrm{PM}$ while A. mellifera $\mathrm{L}$. started foraging at 7.29 $\pm 0.28 \mathrm{AM}$ and ceased at $4.48 \pm 0.13 \mathrm{PM}$. Similarly, on rapeseed, A. cerana $\mathrm{F}$. started foraging at $6.52 \pm 0.12 \mathrm{AM}$ and ceased at $5.07 \pm 0.01 \mathrm{PM}$ while $A$. mellifera $\mathrm{L}$ started foraging at $6.59 \pm 0.38 \mathrm{AM}$ and ceased their foraging at $4.48 \pm 0.12 \mathrm{PM}$. He stated that $A$. mellifera L. started their foraging late in the morning and ceased early in the evening as compared to A. cerana $\mathrm{F}$. Also, A. cerana indica was found to be more active in the forenoon than afternoon (Panda et al., 1991). Abrol (1998) found that solar radiation directly influenced the activity of $A$. cerana $\mathrm{F}$. while solar radiation and light intensity influenced the activity of A. mellifera $\mathrm{L}$.

The duration of foraging per day was found to be $8.34 \pm 0.9$ hours in A. cerana F. and $8.25 \pm 0.9$ hours in A. mellifera $\mathrm{L}$. Thus, A. cerana $\mathrm{F}$. spend about 9 minutes more time in foraging per day than $A$. mellifera $\mathrm{L}$. That means $A$. cerana F. was $1.8 \%$ more efficient on foraging duration than $A$. mellifera L. Dhakal (2003) compared the duration of foraging by $A$. cerana F., i.e. $9.48 \pm 0.15$ hours/day on buckwheat and $10.18 \pm 0.06$ hours/day on rapeseed while by A. mellifera L. it was $9.19 \pm 0.12$ hours/day on buckwheat and 9.49 \pm 0.11 hours/day on rapeseed. Verma and Partap (1993) also found that more foraging duration by A. cerana F. than A. mellifera L. on mustard (Brassica juncea L.). Verma and Dutta (1986) reported that A. cerana F. had long working hours than A. mellifera L. in apple. These findings support to present result and confirm that the behavior of both species of honeybees on buckwheat is similar to mustard and apple. The details about initiation and cessation of foraging as well as foraging duration by Apis cerana $\mathrm{F}$. and Apis mellifera L. on buckwheat are shown in Table 1

Table 1: Initiation and cessation of foraging by honeybees at Meghauli, Chitwan, Nepal 2012/13

\begin{tabular}{llll}
\hline Parameters & $\begin{array}{l}\text { Native bee } \\
\text { (Apis cerana } \text { F.) }\end{array}$ & $\begin{array}{l}\text { European bee } \\
\text { (Apis mellifera } \mathbf{L .} \text { ) }\end{array}$ & CV \% \\
\hline Initiation of foraging & $8.24 \pm 0.11 \mathrm{AM}$ & $8.29 \pm 0.14 \mathrm{AM}$ & 2.44 \\
Cessation of foraging & $5.18 \pm 0.13 \mathrm{PM}$ & $4.56 \pm 0.13 \mathrm{PM}$ & 4.20 \\
Duration of foraging (hrs) & $8.34 \pm 0.30$ & $8.25 \pm 0.15$ & 4.64 \\
\hline
\end{tabular}

The value after \pm indicates S.D. in foraging time in minutes, CV means Coefficient of Variation. 


\section{Number of honeybees entering and outgoing from the hive}

The number of Apis cerana F. and Apis mellifera L. bees entered into the hive in five minutes was the highest (51.69 \pm 0.45 in Apis cerana F., and $62.81 \pm 0.45$ in Apis mellifera L.) at 12 Noon while lowest (11.24 \pm 0.11 in Apis cerana F., and $5.89 \pm 0.11$ in Apis mellifera L.) at $5 \mathrm{PM}$ and no activity was started at 8 AM. Likewise, the number of Apis cerana $\mathrm{F}$. and Apis mellifera L. bees outgoing from the hive in five minutes was the highest (42.67 \pm 0.98 in Apis cerana F. and $48.71 \pm 0.98$ in Apis mellifera L.) at 12 Noon and the lowest (4.31 \pm 0.07 in Apis cerana F. and $2.39 \pm 0.07$ in Apis mellifera L.) at $5 \mathrm{PM}$. This means the foraging peak is 12 Noon in both species of honeybees. This result is also supported by the findings of Dhakal (2003) on buckwheat and mustard. Statistically, there was no significant difference in returning of honeybees into the hive and going out from the hive in both species. This means that the foraging peak was 12 Noon in both species of honeybees in buckwheat (Table 2).

\section{Number of flowers visited by honeybees per minutes}

There was no significance difference on the number of flowers visited by two species of honeybees, Apis cerana $\mathrm{F}$. and Apis mellifera L. The number of buckwheat flower visited by Apis cerana F. was highest at 10 AM while by Apis mellifera L. it was highest at 12 Noon. But, for both species of honeybees it was lowest at 4 PM (Table 3).

This might be due to the effect of high solar radiation at 10 AM influenced the more flower visiting activity of $A$. cerana $\mathrm{F}$. while at 12 Noon high solar radiation and high light intensity influenced more flower visiting activity of $A$. mellifera L. (Abrol, 1998).

Table 2: Number of honeybees entering and outgoing from the hive at Meghauli, Chitwan, Nepal 2012/13

\begin{tabular}{|c|c|c|c|c|c|c|}
\hline \multirow{2}{*}{ Time } & \multicolumn{3}{|c|}{ Entering into the hives } & \multicolumn{3}{|c|}{ Outgoing from the hives } \\
\hline & Apis cerana $\mathbf{F}$. & Apis mellifera $\mathbf{L}$. & CV \% & Apis cerana $\mathbf{F}$. & Apis mellifera $\mathbf{L}$. & CV \% \\
\hline $8 \mathrm{AM}$ & 0 & 0 & - & 0 & 0 & - \\
\hline $9 \mathrm{AM}$ & $16.02 \pm 1.35$ & $9.83 \pm 0.93$ & 32.38 & $15.71 \pm 1.16$ & $14.16 \pm 0.79$ & 25.72 \\
\hline 12 Noon & $51.69 \pm 1.64$ & $62.81 \pm 1.89$ & 23.39 & $42.67 \pm 2.02$ & $48.71 \pm 3.1$ & 38.70 \\
\hline $2 \mathrm{PM}$ & $36.72 \pm 1.47$ & $22.34 \pm 1.39$ & 26.52 & $27.96 \pm 1.7$ & $23.37 \pm 1.26$ & 29.50 \\
\hline $5 \mathrm{PM}$ & $11.24 \pm 0.85$ & $5.89 \pm 0.89$ & 30.21 & $4.31 \pm 0.90$ & $2.39 \pm 0.45$ & 39.14 \\
\hline
\end{tabular}

The value after \pm indicates S.D. in number of bees, CV means Coefficient of Variation.

Table 3: Number of flowers visited by honeybees per minutes at Meghauli, Chitwan, Nepal 2012/13

\begin{tabular}{lllc}
\hline Time & No. of flowers visited by Apis cerana $\mathrm{F}$. & No. of flowers visited by Apis mellifera $\mathrm{L}$. & $\mathrm{CV} \%$ \\
\hline $10 \mathrm{AM}$ & $18.14 \pm 1.46$ & $16.00 \pm 3.00$ & 13.83 \\
$12 \mathrm{Noon}$ & $16.14 \pm 1.95$ & $17.86 \pm 2.54$ & 13.34 \\
$2 \mathrm{PM}$ & $10.57 \pm 1.51$ & $12.86 \pm 2.41$ & 17.17 \\
$4 \mathrm{PM}$ & $5.29 \pm 2.21$ & $4.57 \pm 1.27$ & 36.64
\end{tabular}

The value after \pm indicates S.D. in number of flowers visited per minutes, CV means Coefficient of Variation.

Table 4: Time spent by honeybees per flower at Meghauli, Chitwan, Nepal 2012/13

\begin{tabular}{llll}
\hline \multirow{2}{*}{ Time } & \multicolumn{2}{c}{ Time spent in seconds } & \multirow{2}{*}{ CV \% } \\
\cline { 2 - 4 } & Native honeybee (Apis cerana F.) & European honeybee (Apis mellifera L.) & \\
\hline 10 AM & $2.12 \pm 0.67$ & $2.46 \pm 0.47$ & 25.09 \\
12 Noon & $1.86 \pm 0.56$ & $2.36 \pm 0.63$ & 28.12 \\
2 PM & $2.11 \pm 0.64$ & $2.71 \pm 0.49$ & 23.68 \\
4 PM & $1.71 \pm 0.30$ & $1.93 \pm 0.19$ & 13.89 \\
\hline
\end{tabular}

CV means Coefficient of Variation in time in seconds. 


\section{Time spent by honeybees per flower}

There are statistically no significant differences between two species of honeybees on time spent per flower on buckwheat. But, slightly more time was taken by Apis mellifera L. than Apis cerana F. per floral visit.

A. cerana $\mathrm{F}$. bee spent on an average of 1.95 seconds per flower while A. mellifera L. bee spent on an average of 2.37 seconds per flower of buckwheat. This finding corroborates with the findings of Verma and Dutta (1986) on apple bloom and Desh Raj and Rana (1994) on rapeseed bloom. The details of the observed values are given in Table 4 .

\section{Conclusion}

Apis cerana $\mathrm{F}$. started their foraging early in the morning and ceased late in the evening in comparison to Apis mellifera L. Also, A. cerana $\mathrm{F}$. spent about 9 minutes more time in foraging per day than A. mellifera $\mathrm{L}$. That means $A$. cerana $\mathrm{F}$. was $1.8 \%$ more efficient on foraging duration than A. mellifera L. Both species of honeybees started foraging (entering into the hive and outgoing from the hive) after 8 AM with foraging peak at 12 Noon. The number of buckwheat flowers visited per minute by Apis cerana F. and Apis mellifera L. were highest at 10 AM and 12 Noon, respectively. A. cerana F. bee spent on an average of 1.95 seconds per flower while A. mellifera $\mathrm{L}$. bee spent on an average of 2.37 seconds per flower of buckwheat.

So, buckwheat cultivation is suggested in combination with bee keeping especially Apis cerana F. than Apis mellifera L. because Apis cerana $\mathrm{F}$. is more efficient in foraging than Apis mellifera $\mathrm{L}$. and pollination values more than other hive products.

\section{References}

Abrol DP (1998) Environmental factors influencing flight activity in honeybees, Apis cerana indica $\mathrm{F}$. and Apis mellifera $\mathrm{L}$. (Hymenoptera: Apidae). Indian Bee Journal 60(2): 71-75.

Bjorkman T (1995) The role of honeybees (Hymenoptera: Apidae) in the pollination of buckwheat in eastern North America. Journal of Economic Entomology 88: 1739-1745. DOI: 10.1093/jee/88.6.1739

Davydova NS (1954) Analysis of honeybee pollen loads from buckwheat. Uchenye zapiski kishinevskii universitet 13: 167-173.
Dhakal G (2003) Efficiency of Apis mellifera L. and Apis cerana F. for pollinating mustard and buckwheat. M. Sc. Thesis submitted to Institute of Agriculture and Animal Sciences, Rampur, Chitwan, Nepal. 59p.

Gomez KA and Gomez AA (1984) Statistical procedures for agricultural research. $2^{\text {nd }}$ ed. John Wiley and Sons, Inc. New York, USA. 680 p.

Joshi BD and Rana JC (1999) Status of buckwheat in India. Fagopyrum 16: 7-11.

Marshall HG and Pomeranz Y (1982) Buckwheat: description, breeding, production and utilization. In: Y. Pomeranz (ed.) Advances in Cereal Science and Technology (5), American Association of Cereal Chemist. Incorporated Inc., St. Paul, Minnesota, USA. pp. 157-210.

MoAD (2012) Statistical information on Nepalese agriculture 2012. Government of Nepal, Ministry of Agricultural Development. Agri-business Promotion and Statistics Division, Singha Durbar, Kathmandu, Nepal. 151p.

Panda P, Panda B and Sontakke BK (1991) Foraging behaviour of honeybees on sunflower (Helianthus annuus L.) sown of different dates. Indian Bee Journal 53: 44- 49.

Phillips EF and Demuth GS (1922) Beekeeping in the buckwheat region. U.S. Department of Agricultural Farmers' Bulletin 1216: 26.

Raj D and Rana VK (1994) Time spent by Apis mellifera L. and Apis cerana indica $\mathrm{F}$. foragers on rapeseed bloom. Journal of Entomology Research 18: 335-339.

Rajbhandari BP (2010) Buckwheat in the land of Everest. Himalayan College of Agricultural Sciences and Technology (HICAST), Kathmandu, Nepal. 132p.

Rajbhandari BP and Bhatta GD (2008) Food crops. Agro-ecology and modern agro-techniques. Himalayan college of agricultural sciences and technology (HICAST), Kathmandu, Nepal. 266p.

Robinson WE and Morse RA (1989) The value of honeybees as pollinators of US crops. American Bee Journal 129 (1): 477-487.

Verma LR and Dutta PC (1986) Foraging behavior of Apis cerana indicia and Apis mellifera in pollinating apple flowers. Journal of Apicultural Research 25:197-201.

Verma LR and Pratap U (1993) The Asian hive bee, Apis cerana F., as a pollinator in vegetable seed production. An awareness handbook. ICIMOD, Lalitpur, Nepal. 52p. 